\title{
The Present Status of the Management of Colon and Rectal Cancer in Nigeria
}

\author{
David O. Irabor, ${ }^{1}$ O. Oludolapo Afuwape, ${ }^{2}$ and Omobolaji O. Ayandipo ${ }^{3}$ \\ ${ }^{1}$ Gastrointestinal Surgery Division, Department of Surgery, College of Medicine, University of Ibadan, Oyo State, Nigeria \\ ${ }^{2}$ Gastrointestinal Surgery Division, College of Medicine, University of Ibadan, Ibadan, Nigeria \\ ${ }^{3}$ Hepatobiliary and Endocrine Surgery Division, College of Medicine, University of Ibadan, Ibadan, Nigeria
}

Correspondence should be addressed to David O. Irabor; dirabor@comui.edu.ng

Received 26 May 2014; Revised 8 July 2014; Accepted 24 July 2014; Published 21 August 2014

Academic Editor: Shoji Natsugoe

Copyright (C) 2014 David O. Irabor et al. This is an open access article distributed under the Creative Commons Attribution License, which permits unrestricted use, distribution, and reproduction in any medium, provided the original work is properly cited.

\begin{abstract}
Aim. To demonstrate the possibility of the uniqueness of colorectal cancer (CRC) in the native Nigerian by looking at the different facets of the challenges that management of this disease presents in a tertiary-care hospital in Ibadan, Nigeria. Method. A cohort study starting in 2009 where patients were seen in the out-patient's clinic. All patients who presented with features suggestive of colon or rectal cancer were studied. Biopsies were performed to confirm CRC (especially rectal cancer); patients were then booked for admission and subsequent operation. Patients were excluded if the histopathology of a resected or biopsied mass turned out to be noncancerous or inflammatory. Demographic data like age and sex were recorded. The type of operation done, findings at surgery, and the histopathology of the resected specimen were all recorded. The time taken for the pathology department to process the biopsy and resected specimens was also recorded. Results. 120 patients with CRC were seen over the study period of 5 years (20092013) giving an average of 24 patients per annum. The male : female ratio was $1: 1.14 .86(71.7 \%)$ patients had rectal cancer while the remaining $34(28.3 \%)$ had colon cancer. Most of the colon cancer cases were in the 51-60 age group. The rectum : colon ratio was $2.5: 1.31 \%$ of the patients were 40 years and below. $37 \%$ of those with rectal cancer were 40 years and below. $50 \%$ of resected specimens were Duke's B and above. $45 \%$ of patients had tumors with unfavorable grade or biology (mucinous $21.7 \%$, signet ring $8.3 \%$, and poorly differentiated $15 \%$ ). Only $24 \%$ of patients below 40 years and $41 \%$ of those above 40 years with confirmed rectal carcinoma presented for operation. Conclusion. Advanced tumors at presentation may not always be as a result of late presentation. Unusual aggressiveness of the tumors may lead to rapid progression of the disease. Increasing incidence in younger patients makes abdominoperineal excision of the rectum difficult for such patients to accept.
\end{abstract}

\section{Introduction}

The effective treatment of colorectal cancer (CRC) in subSaharan Africa is hampered by the advanced state of the disease when the patients present to hospital. Poverty and ignorance are the two factors indicted. In the past, access to tertiary medical care was the 3rd factor; however in Nigeria where there are 36 federal tertiary hospitals that is no longer a factor. Nigeria has a population of about a little over 160 million people [1]. The crude incidence of colorectal cancer (CRC) in sub-Saharan Africa has been found to be 4.04/ 100,000 population (4.38 for men and 3.69 for women) [2]. However that of Nigeria has been estimated at 3.4 per 100,000 population [3].
33 years ago, about 18 patients were seen annually (1980) thus raising the notion that the incidence of CRC is increasing in Nigeria $[4,5]$. Indeed, data of CRC from the cancer registry in UCH Ibadan during the period 2005-2009 yielded an annual incidence of 50-70 patients [5]. Even though the load of Nigerian CRC patients is significantly smaller than those of the developed countries [6-8], effective delivery of appropriate treatment to involved patients experiences significant challenges.

The observed major challenges in effective and appropriate CRC treatment are late presentation of the patients, significant involvement of younger patients, aggressive tumor type, lack of tailored/targeted therapy, intrahospital obstacles, 
and the patients' aversion to unfavorable sequelae of surgical treatment.

This study illustrates challenges in our experience with 120 CRC patients who presented to our unit over the last 5 years (2009-2013).

\section{Method}

This was a prospective cohort study which commenced in January 2009 till December 2013. Patients who had clinical features suggestive of colon or rectal cancer were seen at the surgical out-patients clinic or through the Emergency Department of the University College Hospital (UCH), Ibadan. The UCH, Ibadan, an 850-bed hospital, is a tertiarycare institution located in the largest city in West Africa (Ibadan). The hospital serves the whole of Ibadan (population of 2.5 million) and its environs and also receives referrals from all over Nigeria; 170 beds out of the total are reserved for surgical cases. These patients were interviewed and examined by the gastrointestinal surgeons. A confirmatory diagnosis was through barium enema or colonoscopy and biopsies were taken. All patients with confirmed colon or rectal carcinoma were included in this study. Demographic data like age and sex were recorded and the patients were booked for admission and subsequent operation. The findings at surgery, type of operation performed, and the histopathology of the resected specimens (or intraoperative biopsies for the inoperable cases) were recorded. The only patients that were excluded were those who had noncancerous or inflammatory lesions after histopathology reports were available. The turnaround time (TAT) for the pathology department was recorded also.

\section{Results}

We studied 120 confirmed CRC patients over the 5-year period which made an average of 24 patients per annum with an age range of $18-85$ years. The average age was 50.1 years with a male : female ratio of $1: 1.14$. There were 86 rectal cancer and 34 colon cancer patients giving a rectum to colon ratio of $2.5: 1$.

We noticed a significant involvement of younger patients even though the peak age was 51-60 years (Figure 1). A breakdown of the young patients with colon and rectal cancer in this series showed that $3.3 \%$ of patients were 20 years and below (male: female ratio was $3: 1$ ), $13.3 \%$ were 30 years and below ( $\mathrm{M}: \mathrm{F}$ ratio was $1: 1$ ), and $31 \%$ were 40 years and below $(\mathrm{M}: \mathrm{F}$ ratio was $1: 1.5) .36 \%$ of patients with rectal carcinoma were 40 years and below. Most of the colon cancer cases were in the 51-60 age group. Out of these 120 patients, 61 turned up for their various operations. There were 22 abdominoperineal excisions of the rectum, 16 right hemicolectomies, 11 anterior resections, 6 diverting colostomies for inoperability, 3 low anterior resections, and 3 left hemicolectomies. Roughly $75 \%$ of confirmed rectal cancer cases did not show up for surgery. The extent of late presentation is reflected by the status of the resected specimens and this showed that roughly $50 \%$ of all resected tumors were Duke's B and above.

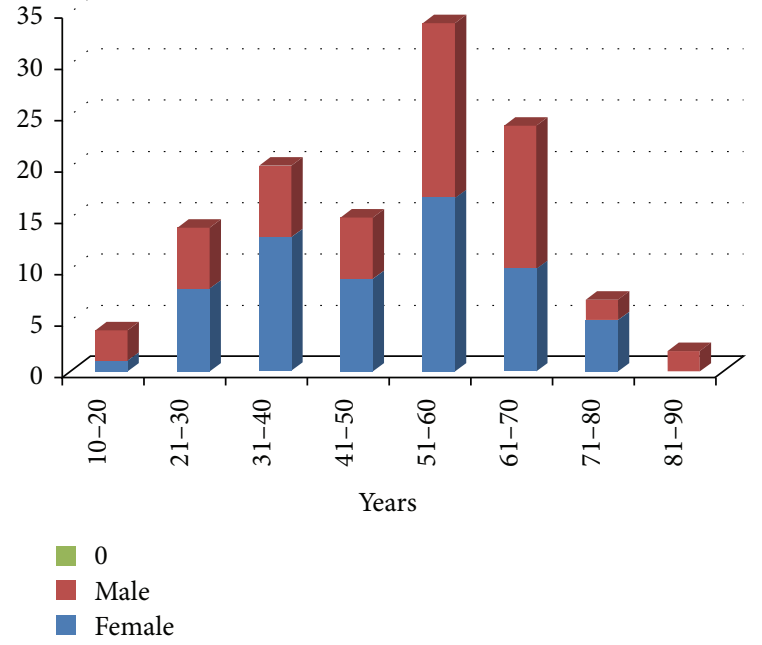

FIGURE 1: Showing age ranges and peak age group of all patients with colon and rectal cancer.

CRC tumour grade/biology: $45 \%$ of the tumors had unfavorable histopathologic type or grade with the mucinous type being $21.7 \%$, poorly differentiated; $15 \%$ and Signet ring type at $8.3 \%$.

Pathology department turnaround time (TAT) for biopsy reports: this showed a range of 2 to 87 days, mean of 15.7 days, median of 11 days, and a mode of 7 days. The TAT for resected specimens showed a range of 6 to 107 days, mean of 29 days, median of 20 days, and a mode of 6 days.

\section{Discussion}

Numerous authors have remarked on the consistent late presentation of cancer patients in the 3rd world, sub-Saharan Africa in particular [9-13]. The mean time of duration of symptoms before presentation to hospital has been recorded to be from 8 to 15 months $[10,12,14]$. This situation is multifactorial and some key factors are ignorance, poverty, and gullibility.

(i) Late Presentation. Ignorance, poverty, and gullibility lead to unfavorable health-seeking behavior [15-17]. Indeed a major problem in Nigeria is that the concept of malignancy has no correlation in the ethnic languages or vernacular. The property of malignant tissue to infiltrate tissue and metastasize is lost on many patients; thus unless there is pain or serious impairment to contiguous organs from the sheer size of the tumors, they will not come to hospital. In this part of the world, rectal bleeding falls under the umbrella of "jedijedi." Jedi-jedi is a spectrum of diseases like diarrhoea, dysentery, low-back pain, hemorrhoids, and pruritus ani. "Agbo jedi" which is the native brew for this ailment is popular and is sold widely $[18,19]$. Patients always vouch for its efficacy until the tumour dictates differently by causing pain, incontinence, or large bowel obstruction. The extent of late presentation is reflected by the status of the resected specimens as roughly $50 \%$ of these were Duke's B and above (Table 1 ). 
TABLE 1: Approximately 50\% $(\mathrm{C}+\mathrm{D})$ of resected tumors were advanced.

\begin{tabular}{lcccc}
\hline \multirow{2}{*}{ Anatomical site } & \multicolumn{5}{c}{ Duke's grading } \\
& A & B & C & D \\
\hline Caecum & - & 5 & 5 & \\
Ascending colon & - & 2 & 3 & \\
Hepatic flexure & - & & 1 & 1 \\
Transverse colon & - & 2 & 1 & \\
Splenic flexure & - & 2 & & \\
Descending colon & - & 1 & & \\
Sigmoid colon & - & 4 & 1 & 2 \\
Rectosigmoid junction & - & 2 & 2 & \\
Rectum & - & 13 & 12 & 2 \\
\hline Total (\%) & - & $31(50.8)$ & $25(41)$ & $5(8.2)$ \\
\hline
\end{tabular}

A sizeable part of this problem is contributed by poverty $[15,17]$. Lack of purchasing power keeps orthodox health care out of the reach of many of these patients. Screening methods for colon and rectal malignancies are not cheap and those that manage to scrape up money for these procedures, for example, colonoscopy or barium enema, subsequently cannot meet the financial obligations for definitive surgery and adjuvant treatment. Thus the cheaper options of alternative medicine are pursued vigorously. Regrettably one has to use the word gullibility and unfortunately it is most apt in these circumstances. Nigeria is said to be the 2nd most religious country after Ghana, and these religious beliefs influence the health-seeking behavior of patients with serious illnesses [16]. Many patients seek healing in church while most seek healing both in church and through traditional medicine. They present to orthodox medicine (UCH, Ibadan) when nothing more can be done. UCH, Ibadan, is known among the populace as "the place you go to die." This is tragic because indeed that is what happens. Inoperable terminal colon or rectal cancer can only receive palliative treatment. Researchers in Nigeria have shown that education status is not an obstacle to the use of alternative medicine for serious ailments [20].

Apart from these key factors it is now becoming apparent that other challenges to colon and rectal cancer management in Nigeria are presenting. Even if health care was made free, public awareness was raised to impressive levels and patients presented early to orthodox hospitals instead of churches and native medicine establishments; this next set of factors could still make the treatment of CRC less than satisfactory.

These factors include the occurrence of $\mathrm{CRC}$ at younger age groups, unusual aggressiveness of these tumors, yet undetermined genetic signature of CRC in native Nigerians and the unpalatable sequelae of extirpative operations sometimes necessary for treatment of the disease (from our results we see a 2:1 rectum to colon ratio; thus more APERs are performed).

(ii) Significant Involvement of Younger Patients. The occurrence of CRC at a significantly younger age in Nigerians than Caucasians, with particular mention of the high proportion of those under 30 years of age, has been reported by several
TABLE 2: $36 \%$ of rectal cancer patients were 40 years and below.

\begin{tabular}{lcccc}
\hline Age range & M & F & Total & $\%$ \\
\hline $\mathbf{1 0 - 2 0}$ & $\mathbf{1}$ & $\mathbf{1}$ & $\mathbf{2}$ & $\mathbf{2 . 3}$ \\
$\mathbf{2 1 - 3 0}$ & $\mathbf{5}$ & $\mathbf{7}$ & $\mathbf{1 3}$ & $\mathbf{1 5 . 1}$ \\
$\mathbf{3 1 - 4 0}$ & $\mathbf{5}$ & $\mathbf{1 1}$ & $\mathbf{1 6}$ & $\mathbf{1 8 . 6}$ \\
$41-50$ & 4 & 6 & 10 & 11.6 \\
$51-60$ & 11 & 9 & 22 & 25.6 \\
$61-70$ & 10 & 6 & 17 & 19.8 \\
$71-80$ & 1 & 2 & 4 & 4.6 \\
$81-90$ & 2 & 0 & 2 & 2.3 \\
\hline
\end{tabular}

TABLE 3: Significant proportion of unfavorable tumor type in the patients.

\begin{tabular}{lcc}
\hline Tumour grading/type & Number & $\%$ \\
\hline Well differentiated & 30 & 25 \\
Moderately differentiated & 36 & 30 \\
Poorly differentiated & 18 & 15 \\
Mucinous & 26 & 21.7 \\
Signet ring & 10 & 8.3 \\
\hline
\end{tabular}

authors but no satisfactory reason has been adduced $[4,5,21-$ 23]. The life expectancy of Nigerians being put as 45 years for males and 47 years for females may influence the development of these tumors at a younger age than Caucasians. Conversely, the development of these tumors at a younger age may be responsible for a short life expectancy [5]. This present study showed roughly that a little over a third of the patients with rectal cancer were below 40 years of age with $17.4 \%$ of all the patients being younger than 30 years (Table 2). This, to our minds, is certainly not a negligible statistic as read in some authors' reports [2]. This age group is one that is likely to refuse operations that may lead to sexual dysfunction and/or a permanent colostomy. However one should be aware that the age standardization of CRC incidence in sub-Saharan Africa still shows that it increases with age, so that while the crude annual incidence (per 100,000) for age group 35-44 is recorded as 3.48, that of age group 65-74 is 34.37 [2]. Since the population structure of Nigeria has more young and middleaged people than the elderly, many in the middle-age group may manifest this disease.

(iii) Aggressive Tumor Type. From our results one will see that almost half of the patients (45\%) had unfavorable tumour grade or histopathology (Table 3). This study shows a high incidence of mucinous and signet ring forms $(21.7 \%$ and $8.3 \%$, resp.). Several reports from the developed countries show a range of mucinous adenocarcinoma of 6-20\% [24, 25]. Kano, a cosmopolitan city in northern Nigeria, reported $30 \%$ of the mucinous type [26] while Jos in the middle belt reported 33\% mucinous forms [27]. It has also been reported that the CRC seen in patients under 30 years seem to have a higher percentage of tumors with unfavorable/aggressive behavior and this translates into poorer prognoses $[28,29]$. There seems to be a higher incidence of mucinous and anaplastic colorectal 
tumors in parts of Africa than in American or British series [27]. Indeed we are now seeing metastases different from hitherto hepatic metastases and ascites. Pulmonary (dyspnoea), cerebral (hemiplegia), and spinal (paraplegia) metastases are occurring more frequently. We are also seeing more patients with carcinomatosis peritonei. The relative lack of premalignant factors for CRC in the native African has suggested a different pathway from Caucasians. The adenomacarcinoma sequence has not been strongly considered as a pathway because of the rarity of adenomatous polyps and chronic inflammatory bowel diseases in the native Nigerian [10-12, 21, 30-32] and indeed in the native African [33]. Some authors have actually hypothesized that maybe the carcinoma appears de novo in a bid to explain why there may be a rarity of adenomatous polyps in the native African [34-36]. Hereditary nonpolyposis colon cancer (HNPCC) has a strong attraction as an etiological pathway, perhaps because of the attributes of involvement of younger patients, and increased presence of mucinous and signet ring types; however the drawback is that a family history remains unproven in the majority of these patients. Nevertheless a study involving a few Nigerian patients with CRC suggests that HNPCC may be more frequent than hitherto known $[37,38]$. A study in South Africa also suggests that HNPCC may be a viable pathway but admits that it is often problematic to obtain family history from affected individuals in developing countries due to factors such as language barriers, fears of isolation, and being prejudiced against [39]. Another possible etiological pathway that may be relevant to the native Nigerian is the serratedneoplasia pathway. This is one area that may need deeper study because carcinomas that arise from these serrated adenomata are known to develop rapidly and are aggressive $[40,41]$. Thus such patients may always present with advanced tumors. Serrated adenomas are also notoriously difficult to detect during routine colonoscopy because they are flat and may resemble mucosal folds [40]. Studies on other cancers like breast and prostate have also suggested that African types may be more aggressive $[42,43]$.

(iv) Intrahospital Obstacles. Some of the intrahospital processes also conspire to produce difficulty in efficient service; for example, our pathology turnaround time could improve. The College of American Pathologists (CAP) recommends 2 days for elective specimen reports to be released and maximum of 1 week for those that may need special stains or tests [44]. However our series showed a mean TAT of 15.7 days for biopsy results while for resected specimens the mean TAT was 29 days. This results in delay in commencing ablative treatment in cases of rectal carcinoma and also delay in chemotherapy and radiotherapy. The phenomenon of "lost to follow-up" also affects self-auditing of our efforts because accurate disease-free intervals, survival, and mortality rates are presently difficult to compile.

(v) Lack of Tailored/Targeted Therapy. The BRAF mutation, KRAS oncogene, and MSI status of colon and rectal cancer are now important for prognosis and guide to treatment. Abdulkareem et al. from Lagos in collaboration with researchers from Leeds have shown the BRAF and KRAS status in 112 CRC paraffin-embedded specimens of native Nigerians. The study showed that $21 \%$ of Nigerian CRC patients carry a KRAS mutation and $4.5 \%$ demonstrated a BRAF V600E mutation [45]. The prevalence of BRAF mutation in Caucasians is $9.6 \%$ and this is known to be associated with increased mortality from the disease [46]. The study by Abdulkareem et al. may imply that Nigerian patients may benefit from anti-EGFR antibody therapy like Cetuximab or Panitumumab, more than Caucasian patients [45]; unfortunately these drugs are out of reach for the majority of Nigerians. A recent study in Ghana, a neighboring West African country, showed a high frequency of MSI-high colorectal tumors (41\%), 32\% of KRAS mutations, and an absence of BRAF mutations [47]. Who knows if the genetic makeup of Nigerian tumors may render current chemotherapy regimens unsuitable or inefficacious? Given the observation that MSI$\mathrm{H}$ CRC may not respond well to 5-fluorouracil chemotherapy $[48,49]$. Having to travel long distances every 3-5 weeks to stay in hospital for 2 days of chemotherapy which on the long run prolongs life for 2-3 months may make one rethink the whole process. We are aware that there exists interethnic variability in response to cytotoxic drugs and there is paucity of information regarding native Africans [50, 51]. How does the pathway of cytotoxic drug resistance differ in native Africans? Are we justified in giving adjuvant chemotherapy to patients with advanced CRC in Nigeria using Caucasianbased dosimetry? These questions can only be answered when cytotoxic chemotherapy studies are done on native Africans.

(vi) Unfavorable Sequelae of Surgical Treatment. In Nigerian males, erectile dysfunction is a major morbidity after an abdominoperineal excision of the rectum (APER) [52]. As we have shown, the ratio of rectal to colon cancer is $2.5: 1$ (Table 4); thus more APERs are done than colectomies. The female patients also have sexual dysfunction ranging from loss of desire to dyspareunia $[53,54]$. Cultural taboos ensure that there is refusal of operations that leave the patient with a permanent colostomy [54]. For both sexes, having a colostomy means difficulty in getting married and having a family which translates to having no voice or standing in the community. For those already married, there exist grounds for rejection with or without humiliation. For the practitioners of Islam, there may be some difficulty in making ablutions for prayer. For the traditionalist, an altered body image has implications for reincarnation. Only $24 \%$ of patients below 40 years and $41 \%$ of those above 40 years with confirmed rectal carcinoma presented for APER (Figure 2). Indeed, patients with terminal colostomies have been known to commit suicide $[4,10]$. Unfortunately when options of surgery are discussed, the patients do not vouchsafe their objections to this treatment; instead they do not show up in hospital on the agreed dates for admission.

In summary, the major challenges are as follows:

(i) late presentation: probably most thorny and may require intense public awareness programs;

(ii) significant involvement of young persons (they are more likely to refuse ablative surgery); 
TABLE 4: Tumor sites in relation to age groups.

\begin{tabular}{|c|c|c|c|c|c|c|c|c|c|c|}
\hline Age range & Caecum & $\begin{array}{c}\text { Ascending } \\
\text { colon }\end{array}$ & $\begin{array}{l}\text { Hepatic } \\
\text { flexure }\end{array}$ & $\begin{array}{c}\text { Transverse } \\
\text { colon }\end{array}$ & $\begin{array}{l}\text { Splenic } \\
\text { flexure }\end{array}$ & $\begin{array}{c}\text { Descending } \\
\text { colon }\end{array}$ & Sigmoid & Rectosigmoid & Rectum & Total \\
\hline $10-20$ & & & & 1 & & & 1 & & 2 & 4 \\
\hline $21-30$ & 1 & & & & & & & & 13 & 14 \\
\hline $31-40$ & 2 & 1 & & & & & 1 & & 16 & 20 \\
\hline $41-50$ & 2 & & 1 & 2 & & & & & 10 & 15 \\
\hline $51-60$ & 1 & 2 & 1 & & 1 & 1 & 3 & 3 & 22 & 34 \\
\hline $61-70$ & 3 & 1 & & & & & 2 & 1 & 17 & 24 \\
\hline $71-80$ & 1 & & & & 1 & & 1 & & 4 & 7 \\
\hline $81-90$ & & & & & & & & & 2 & 2 \\
\hline Total & 10 & 4 & 2 & 3 & 2 & 1 & 8 & 4 & 86 & 120 \\
\hline
\end{tabular}

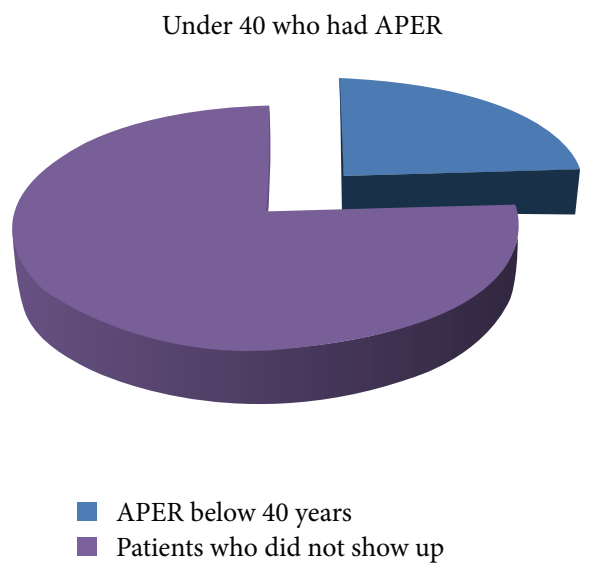

FIGURE 2: Showing proportion of under 40 s who did not turn up for scheduled surgery.

(iii) aggressiveness of tumors (unusual metastases increasing) and lack of genetic signature;

(iv) pathology turnaround time (needs improvement);

(v) benefits or otherwise of cytotoxic chemotherapy (survival statistics not available);

(vi) cultural abhorrence to available treatment (means colostomy repels patients).

What Does This Paper Add to the Literature? This paper shows the possibility of the uniqueness of colorectal cancer (CRC) in the native Nigerian. It underlines the possibility that CRC in the African has a different pathology and as such treatment protocols including chemotherapy should be developed and tailored to benefit the native African.

\section{Conflict of Interests}

The authors declare that there is no conflict of interests regarding the publication of this paper.

\section{Authors' Contribution}

David O. Irabor was responsible for article concept, data collection, data interpretation, literature search, writing, and surgical management of patients involved. O. Oludolapo Afuwape was responsible for data collection, data interpretation, literature search, writing, and comanagement of patients involved. Omobolaji O. Ayandipo was responsible for data collection, data interpretation, literature search, writing, and comanagement of patients involved.

\section{References}

[1] World Statistics Pocket Book, Country Profile: Nigeria, 2013, http://unstats.un.org/unsd/default.htm.

[2] A. Graham, D. Adeloye, L. Grant, E. Theodoratou, and H. Campbell, "The incidence of colorectal cancer in sub-Saharan Africa: a systematic analysis," Journal of Global Health, vol. 2, Article ID 020404, 2012.

[3] J. Sack and J. M. Rothman, "Colorectal cancer: natural history and management," Hospital Physician, vol. 36, pp. 64-73, 2000.

[4] D. Irabor and O. A. Adedeji, "Colorectal cancer in Nigeria: 40 years on. A review," European Journal of Cancer Care, vol. 18, no. 2, pp. 110-115, 2009.

[5] D. O. Irabor, A. Arowolo, and A. A. Afolabi, "Colon and rectal cancer in Ibadan, Nigeria: an update," Colorectal Disease, vol. 12, no. 7, pp. e43-e49, 2010.

[6] A. B. M. Wilmink, "Overview of the epidemiology of colorectal cancer," Diseases of the Colon and Rectum, vol. 40, no. 4, pp. 483493, 1997.

[7] M. Moshkowitz and N. Arber, "Differences in incidence and distribution of colorectal cancer among races and ethnic societies: lifestyle, genes or both?" Digestion, vol. 72, no. 4, pp. 219-222, 2005.

[8] P. Boyle, D. G. Zaridze, and M. Smans, "Descriptive epidemiology of colorectal cancer," International Journal of Cancer, vol. 36, no. 1, pp. 9-18, 1985.

[9] O. G. Ajao, "Colon and anorectal neoplasms in a tropical African population," International Surgery, vol. 64, no. 2, pp. 47-52, 1979. 
[10] O. O. Adekunle and J. A. Lawani, "Clinical aspects and management of carcinoma of the rectum in Nigerians," East African Medical Journal, vol. 59, no. 3, pp. 206-213, 1982.

[11] O. S. Ojo, W. O. Odesanmi, and O. O. Akinola, "The surgical pathology of colorectal carcinomas in Nigerians," Tropical Gastroenterology, vol. 12, no. 4, pp. 180-184, 1991.

[12] D. O. Akinola and A. O. Arigbabu, "Pattern and presentation of large bowel neoplasms in Nigerians," Central African Journal of Medicine, vol. 40, no. 4, pp. 98-102, 1994.

[13] American Cancer Society, Cancer in Africa, American Cancer Society, Atlanta, Ga, USA, 2011.

[14] K. T. Yawe, A. A. Bakari, U. H. Pindiga, and A. A. Mayun, "Clinicopathological pattern and challenges in the management of colorectal cancer in sub-Saharan Africa," Journal of the Chinese Medical Association, vol. 2, pp. 688-694, 2007.

[15] I. S. Abdulraheem, "Health needs assessment and determinants of health-seeking behaviour among elderly Nigerians: a household survey," Annals of African Medicine, vol. 6, no. 2, pp. 58-63, 2007.

[16] G. B. S. Iyalomhe and S. I. Iyalomhe, "Health-seeking behaviour of rural dwellers in southern Nigeria: implications for healthcare professionals," International Journal of Tropical Disease \& Health, vol. 2, pp. 62-71, 2012.

[17] M. A. Tanimola and J. O. Owoyemi, "Healthcare-seeking behaviour in Anyigba, North Central, Nigeria," Research Journal of Medical Sciences, vol. 3, no. 2, pp. 47-51, 2009.

[18] I. A. Oreagba, K. A. Oshikoya, and M. Amachree, "Herbal medicine use among urban residents in Lagos, Nigeria," BMC Complementary and Alternative Medicine, vol. 11, article 117, 2011.

[19] I. S. Akande, O. A. Adewoyin, U. F. Njoku, and S. O. Awosika, "Biochemical evaluation of some locally prepared herbal remedies (Agbo) currently on high demand in Lagos metropolis, Nigeria," Journal of Drug Metabolism \& Toxicology, vol. 3, p. 118, 2012.

[20] E. R. Ezeome and A. N. Anarado, "Use of complementary and alternative medicine by cancer patients at the University of Nigeria Teaching Hospital, Enugu, Nigeria," BMC Complementary and Alternative Medicine, vol. 7, article 28, 2007.

[21] O. G. Ajao, M. O. Adenuga, and J. K. Ladipo, "Colorectal carcinoma in patients under the age of 30 years: a review of 11 cases," Journal of the Royal College of Surgeons of Edinburgh, vol. 33, no. 5, pp. 277-279, 1988.

[22] A. Z. Sule and B. M. Mandong, "Malignant colorectal tumours in patients 30 years and below: a review of 35 cases," Central African Journal of Medicine, vol. 45, no. 8, pp. 209-212, 1999.

[23] O. O. Adekunle and G. O. Ajao, "Colorectal cancer in adolescent Nigerians," Scandinavian Journal of Gastroenterology, Supplement, vol. 21, no. 124, pp. 183-186, 1986.

[24] L. Xie, P. J. Villeneuve, and A. Shaw, "Survival of patients diagnosed with either colorectal mucinous or non-mucinous adenocarcinoma: a population-based study in Canada," International Journal of Oncology, vol. 34, no. 4, pp. 1109-1115, 2009.

[25] M. Numata, M. Shiozawa, T. Watanabe et al., "The clinicopathological features of colorectal mucinous adenocarcinoma and a therapeutic strategy for the disease," World Journal of Surgical Oncology, vol. 10, article 109, 2012.

[26] S. T. Edino, A. Z. Mohammed, and O. Ochicha, "Characteristics of colorectal carcinoma in Kano, Nigeria: an analysis of 50 cases," Nigerian Journal of Medicine, vol. 14, no. 2, pp. 161-166, 2005.
[27] J. O. Obafunwa, "Pattern of alimentary tract tumours in Plateau State: a middle belt area of Nigeria," Journal of Tropical Medicine and Hygiene, vol. 93, no. 5, pp. 351-354, 1990.

[28] P. L. Chalya, M. D. Mchembe, J. B. Mabula et al., "Clinicopathological patterns and challenges of management of colorectal cancer in a resource-limited setting: a Tanzanian experience," World Journal of Surgical Oncology, vol. 11, article 88, 2013.

[29] O. G. Ajao, I. A. Grillo, T. Malatani, and M. Y. al Shehri, "Colorectal carcinoma in a tropical African population: an overview report," East African Medical Journal, vol. 71, no. 10, pp. 640643, 1994.

[30] Y. Iliyasu, J. K. Ladipo, E. E. U. Akang, C. A. Adebamowo, O. G. Ajao, and P. U. Aghadiuno, "A twenty-year review of malignant colorectal neoplasms at University College Hospital, Ibadan, Nigeria," Diseases of the Colon and Rectum, vol. 39, no. 5, pp. 536-540, 1996.

[31] A. N. Ani, "Anorectal diseases in Western Nigerian adults. A field survey," Diseases of the Colon and Rectum, vol. 26, no. 6, pp. 381-385, 1983.

[32] D. C. Nwafo and J. O. Ojukwu, "Malignant disease of the colon, rectum, and anus in Nigerian Igbos," Annals of the Royal College of Surgeons of England, vol. 62, no. 2, pp. 133-135, 1980.

[33] I. Segal, "Rarity of colorectal adenomas in the African black population," European Journal of Cancer Prevention, vol. 7, no. 5, pp. 387-391, 1998.

[34] K. Jaskiewicz, E. Lancaster, L. Banach, and A. Karmolinski, "Proliferative ability of normal and neoplastic colonic mucosa in population groups with high and low risk for colorectal cancer," Anticancer Research, vol. 18, pp. 4641-4644, 1998.

[35] I. Segal, S. A. R. Cooke, D. G. Hamilton, and L. Ou Tim, "Polyps and colorectal cancer in South African Blacks," Gut, vol. 22, no. 8, pp. 653-657, 1981.

[36] A. van’t Hof, K. Gilissen, R. J. Cohen et al., "Colonic cell proliferation in two different ethnic groups with contrasting incidence of colon cancer: is there a difference in carcinogenesis?" Gut, vol. 36, no. 5, pp. 691-695, 1995.

[37] C. A. Adebamowo, O. Adeyi, R. Pyatt, T. W. Prior, R. B. Chadwick, and A. de la Chapelle, "Case report on hereditary non-polyposis colon cancer (HNPCC) in Nigeria," African Journal of Medicine and Medical Sciences, vol. 29, no. 1, pp. 71-73, 2000.

[38] W. F. Anderson, A. Umar, and O. W. Brawley, "Colorectal carcinoma in black and white race," Cancer and Metastasis Reviews, vol. 22, no. 1, pp. 67-82, 2003.

[39] L. Cronje, P. J. Becker, A. C. Paterson, and M. Ramsay, "Hereditary non-polyposis colorectal cancer is predicted to contribute towards colorectal cancer in young South African blacks," South African Journal of Science, vol. 105, no. 1-2, pp. 68-72, 2009.

[40] R. Makkar, R. K. Pai, and C. A. Burke, "Sessile serrated polyps: cancer risk and appropriate surveillance," Cleveland Clinic Journal of Medicine, vol. 79, no. 12, pp. 865-871, 2012.

[41] D. C. Snover, "Update on the serrated pathway to colorectal carcinoma," Human Pathology, vol. 42, no. 1, pp. 1-10, 2011.

[42] O. W. Brawley, "Toward a better understanding of race and cancer," Clinical Cancer Research, vol. 16, no. 24, pp. 5920-5922, 2010.

[43] P. Kheirandish and F. Chinegwundoh, "Ethnic differences in prostate cancer," British Journal of Cancer, vol. 105, no. 4, pp. 481-485, 2011.

[44] A. Ribe, T. Ribalta, R. Lledó, G. Torras, M. A. Asenjo, and A. Cardesa, "Evaluation of turnaround times as a component of 
quality assurance in surgical pathology," International Journal for Quality in Health Care, vol. 10, no. 3, pp. 241-245, 1998.

[45] F. B. Abdulkareem, L. A. Sanni, S. D. Richman, and P. Chambers, "KRAS and BRAF mutations in Nigerian colorectal cancers," West African Journal of Medicine, vol. 31, pp. 198-203, 2012.

[46] G. Safaee Ardekani, S. M. Jafarnejad, L. Tan, A. Saeedi, and G. $\mathrm{Li}$, "The prognostic value of BRAF mutation in colorectal cancer and melanoma: a systematic review and meta-analysis," PLoS ONE, vol. 7, no. 10, Article ID e47054, 2012.

[47] L. Raskin, J. C. Dakubo, N. Palaski, J. K. Greenson, and S. B. Gruber, "Distinct molecular features of colorectal cancer in Ghana," Cancer Epidemiology, vol. 37, pp. 556-561, 2013.

[48] H. Ashktorab, D. T. Smoot, J. M. Carethers et al., "High incidence of microsatellite instability in colorectal cancer from African Americans," Clinical Cancer Research, vol. 9, no. 3, pp. 11121117, 2003.

[49] P. Benatti, R. Gafa, D. Barana, and M. Marino, "Microsatellite instability and colorectal cancer prognosis," Clinical Cancer Research, vol. 11, pp. 8332-8340, 2005.

[50] W. H. Ling and S. C. Lee, "Inter-ethnic differences-how important is it in cancer treatment?" Annals of the Academy of Medicine Singapore, vol. 40, no. 8, pp. 356-361, 2011.

[51] P. H. O’Donnell and M. E. Dolan, "Cancer pharmacoethnicity: ethnic differences in susceptibility to the effects of chemotherapy," Clinical Cancer Research, vol. 15, no. 15, pp. 4806-4814, 2009.

[52] M. A. Aghaji and O. M. Obiekwe, "Sexual function in males following abdomino-perineal resection in Nigeria," Central African Journal of Medicine, vol. 37, no. 9, pp. 301-303, 1991.

[53] M. J. Traa, J. de Vries, J. A. Roukema, and B. L. den Oudsten, "Sexual (dys) function and the quality of sexual life in patients with colorectal cancer: a systematic review," Annals of Oncology, vol. 23, no. 1, pp. 19-27, 2012.

[54] L. M. D. Yusufu, S. Y. Sabo, and V. I. Odigie, "Anorectal cancer involving the female genital tract: the morbidity and implications for sexual function," Nigerian Journal of Surgical Research, vol. 5, pp. 38-42, 2003. 


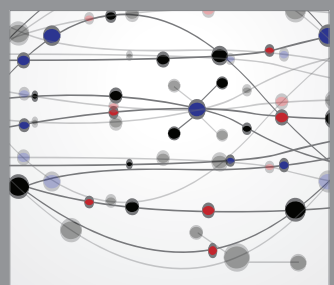

The Scientific World Journal
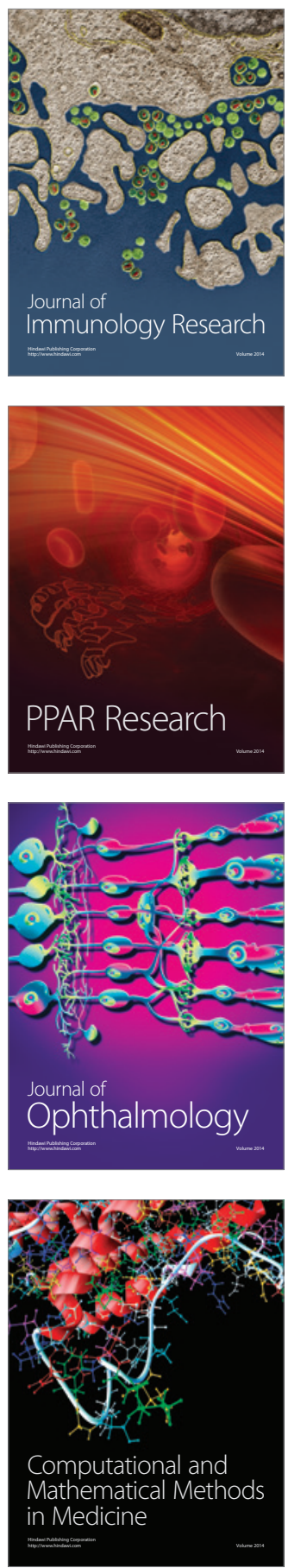

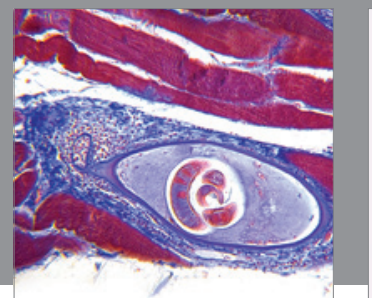

Gastroenterology

Research and Practice
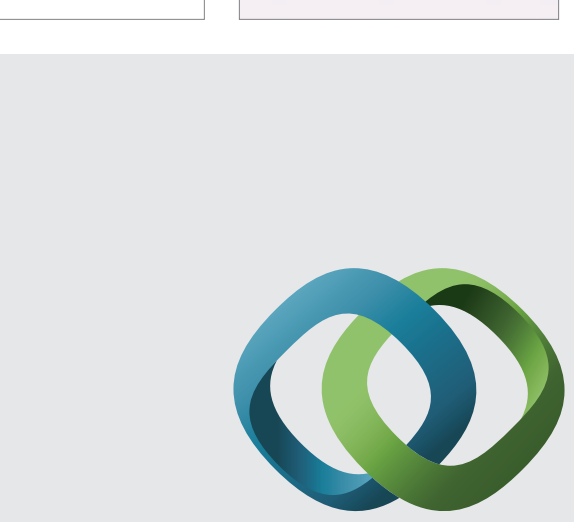

\section{Hindawi}

Submit your manuscripts at

http://www.hindawi.com
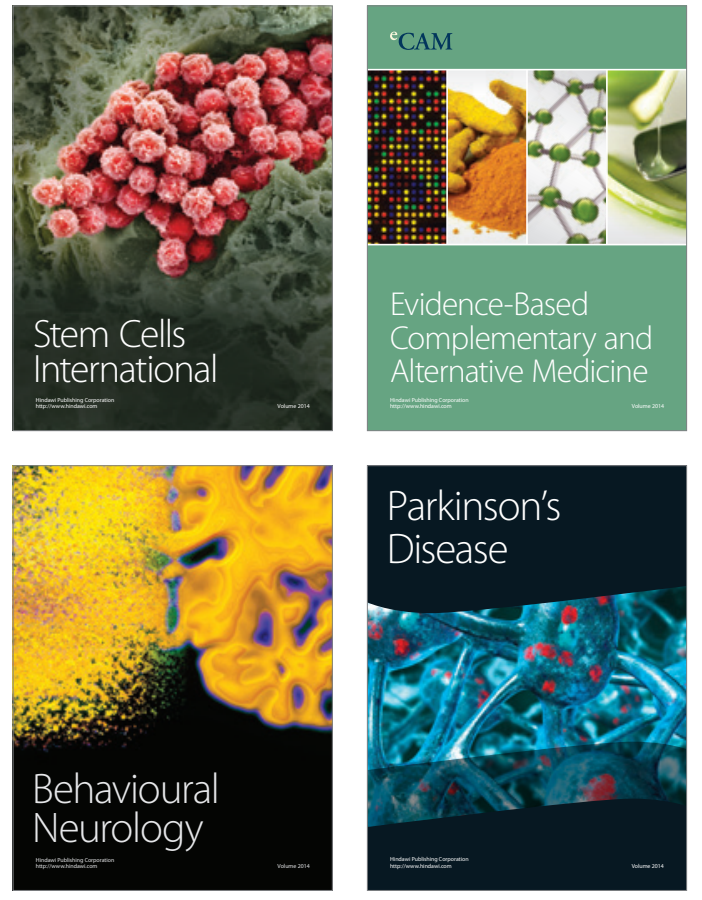
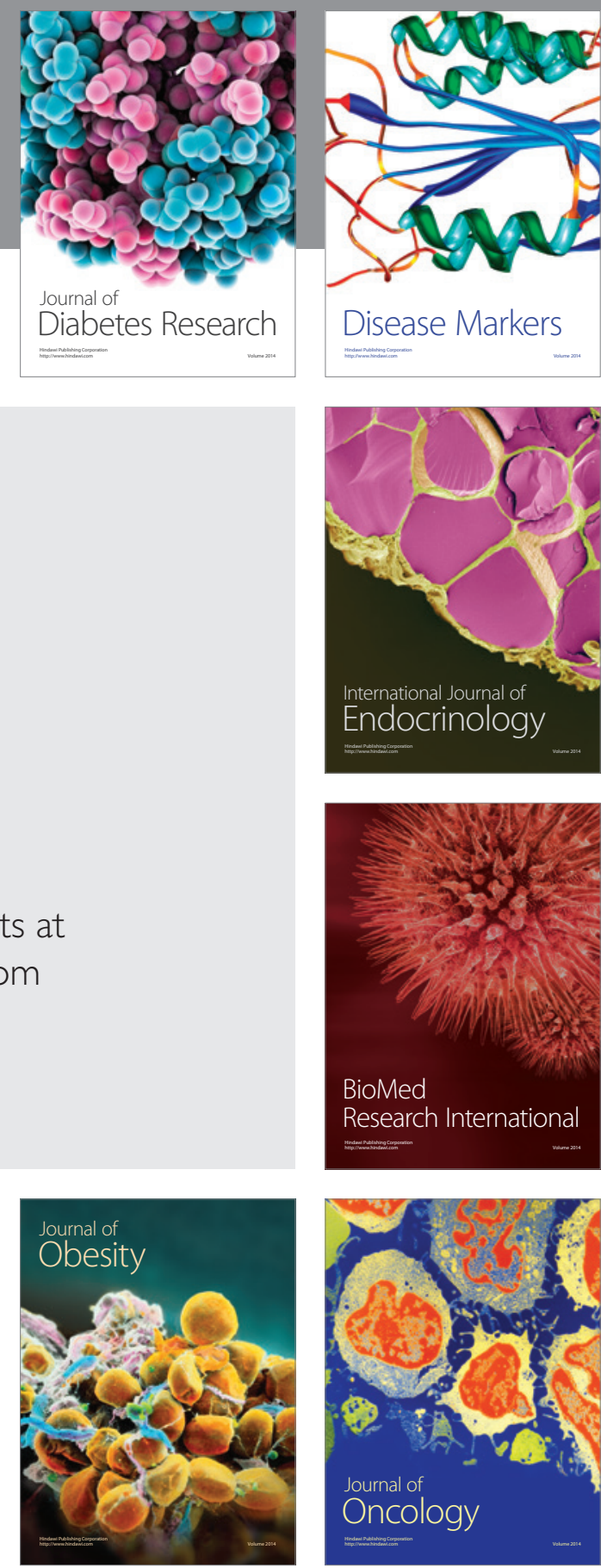

Disease Markers
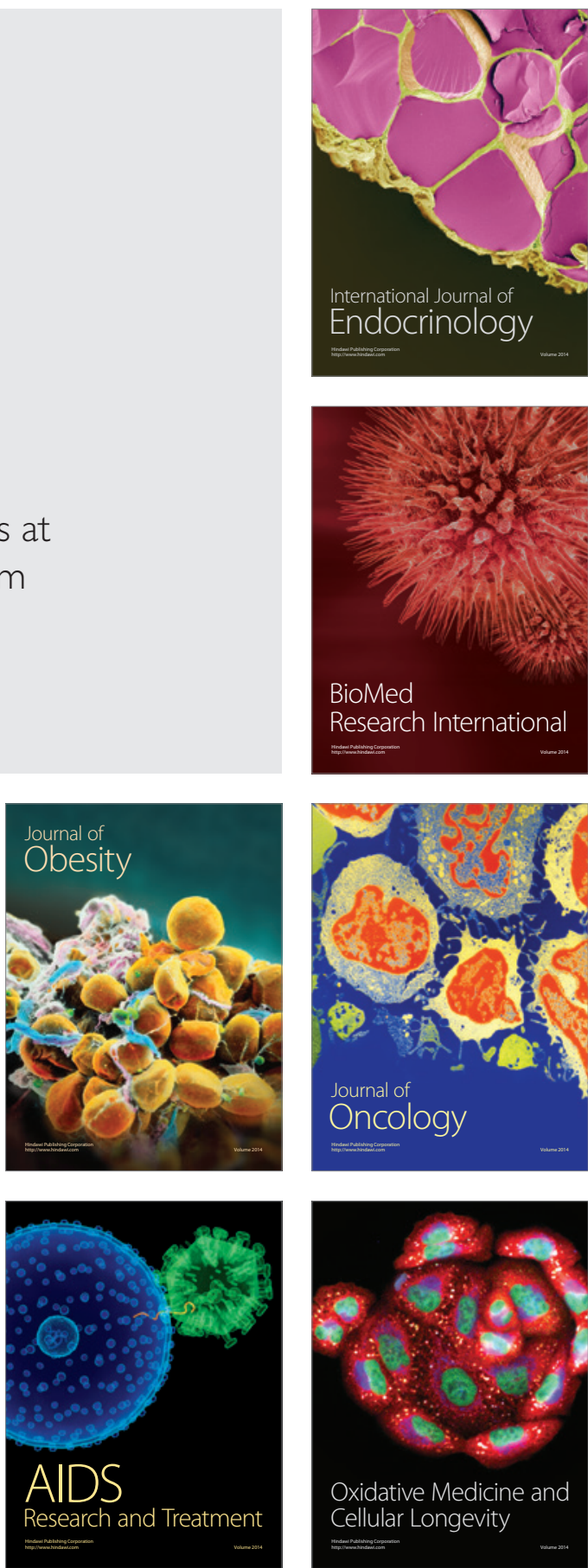